\title{
Coparentalidade e envolvimento parental em famílias binucleares: revisão sistemática
}

\section{Coparentality and Parental Involvement in Binuclear Families: Systematic Literature Review}

\author{
Fernanda Martins de Souza ${ }^{1}$ \\ https://orcid.org/0000-0002-0178-5714 \\ Milena Carolina Fiorini ${ }^{2}$ \\ https://orcid.org/0000-0003-1390-1564 \\ Maria Aparecida Crepaldi ${ }^{3}$ \\ https://orcid.org/0000-0002-5892-7330 \\ 1,2,3 Departamento de Psicologia, Centro de Filosofia e Ciências Humanas, \\ Universidade Federal de Santa Catarina, Brasil
}

\begin{abstract}
Resumo. Objetivo. O objetivo desta revisão sistemática foi compreender como a coparentalidade, o envolvimento parental e as práticas parentais influenciam a dinâmica de famílias binucleares. Método. Realizou-se uma busca nas bases de dados PsycINFO, Web of Science e BVSPsi, que resultou em 17 artigos científicos. Os estudos foram analisados criticamente em relação às características metodológicas e aos principais resultados. Resultados. Em linhas gerais, observou-se que a coparentalidade e o envolvimento parental associam-se com diversos fatores de proteção à saúde psicológica dos pais e das crianças após o divórcio, em consonância com dados encontrados com famílias intactas/nucleares. Não foram encontradas pesquisas sobre práticas parentais dentro dos critérios de busca estabelecidos. Discutem-se possíveis vieses e indicações para futuras investigações e intervenções com famílias binucleares.
\end{abstract}

Palavras-chave. Coparentalidade, envolvimento parental, divórcio, separação conjugal.

Abstract. Objective. The objective of this systematic review was to understand how coparenting, parental involvement, and parenting practices influence the dynamics of binuclear families. Method. A search was carried out in the PsycINFO, Web of Science, and BVSPsi databases, which resulted in 17 scientific articles. The studies were analyzed critically concerning the methodological characteristics and the main results. Results. In general, it was observed that coparenting and parental involvement are associated with several factors that protect the psychological health of parents and children after divorce, in line with data found with intact/ nuclear families. No research was found on parenting practices within the established search criteria. Possible biases and indications for future investigations and interventions with binuclear families are discussed.

Keywords. Coparenting, Parental Involvement, Divorce, Marital separation.

'Fernanda Martins de Souza. Departamento de Psicologia, Centro de Filosofia e Ciências Humanas, Universidade Federal de Santa Catarina, Brasil. Dirección postal: 88.040-970. E-mail: fernanda.martinsds@gmail.com

${ }^{2}$ Milena Carolina Fiorini. Departamento de Psicologia, Centro de Filosofia e Ciências Humanas, Universidade Federal de Santa Catarina, Brasil. E-mail: milenacf.psicologa@gmail.com

${ }^{3}$ Maria Aparecida Crepaldi. Departamento de Psicologia, Centro de Filosofia e Ciências Humanas, Universidade Federal de Santa Catarina, Brasil. .E-mail: maria.crepaldi@ufsc.br

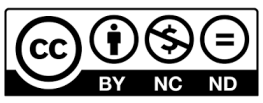

Esta obra está bajo una licencia de Creative Commons Reconocimiento-NoComercial-SinObraDerivada 4.0 Internacional. 


\section{Introdução}

A separação dos pais em famílias com crianças é caracterizada por um rompimento que traz inúmeras mudanças na parentalidade (Lamela, Figueiredo et al., 2010). No entanto, a família continua sendo uma unidade após vivenciar a separação conjugal, sejam elas formais, como o divórcio, ou informais. Ela funciona com dois núcleos, gerenciados por cada um dos progenitores, passando a ser denominada família binuclear (Ahrons, 1994).

A parentalidade, a conjugalidade, e a coparentalidade estão inter-relacionadas e associadas às práticas parentais (Böing \& Crepaldi, 2016). A coparentalidade é definida como a relação entre os pais e/ou cuidadores em suas funções parentais, ou seja, tratase do envolvimento recíproco e conjunto na tarefa de criação e educação dos filhos. Tal relação envolve o compartilhamento de responsabilidades, o apoio mútuo, o apoio à parentalidade do outro e a coordenação entre a díade parental (Feinberg, 2003).

As práticas parentais dizem respeito às estratégias utilizadas pelos pais, com as funções de orientar, controlar ou reforçar os comportamentos da criança, além de socializá-la (Kobarg et al., 2010). Compreendidas sob uma ótica mais ampla, podem envolver diversos fatores, como: promoção de habilidades sociais e valores morais, monitoramento dos filhos tanto no ambiente de casa quanto fora, negociação referente a regras de convivência, formas de punição quando a criança apresenta comportamentos inadequados, responsabilidade, independência, disciplina e autonomia (Kobarg et al., 2010).

O conceito de envolvimento parental, por sua vez, é mais abrangente do que as práticas parentais, e derivou das pesquisas sobre o envolvimento paterno (Grzybowski \& Wagner, 2010), sendo que os dois termos muitas vezes se confundem no contexto dos estudos científicos. O construto envolvimento parental pode ter caráter direto, quando se trata das formas de interação diretamente com a criança (cuidados em geral, brincadeiras e tempo livre dos pais com a criança); e indireto, caracterizado pela acessibilidade e responsabilidade pelo bem-estar do filho (capacidade dos pais de pensar na criança quando não estão com ela e de planejar e organizar a vida da criança, sua saúde, sustento e educação) (Lamb et al., 1985).

Independentemente da configuração familiar, práticas parentais negativas, que podem ser permeadas por violência e/ou permissividade excessiva, impactam negativamente no comportamento do(s) filho(s), aumentando a incidência de problemas comportamentais externalizantes (agressividade, hiperatividade, etc.) (Choe et al., 2013) e internalizantes (depressão, ansiedade, etc.) (Gershoff et al., 2010; Machado \& Mosmann, 2018). Já o emprego de práticas parentais positivas, envolvendo afeto, diálogo e estabelecimento de limites, tende a fortalecer as habilidades sociais e reduzir problemas de comportamento infantil (Choe et al., 2013; Gulliford et al., 2015).

Estudos com famílias binucleares têm evidenciado que o conflito entre os pais é o elemento que exerce maior influência negativa na coparentalidade (Lamela, Castro et al., 2010; Lamela et al., 2013; Machado \& Mosmann, 2019). Já a coparentalidade positiva e cooperativa tem sido referenciada como um forte preditor do envolvimento paterno (Finzi-Dottan \& Cohen, 2016; Souza, 2018). A literatura científica aponta, ainda, a presença de práticas parentais negativas no envolvimento parental de mães divorciadas (Grzybowski \& Wagner, 2010). Já quando a relação entre os pais separados é satisfatória, o envolvimento paterno tende a ser influenciado positivamente, especialmente nas práticas de disciplina dos filhos (Brito et al., 2010; Grzybowski \& Wagner, 2010). 
A revisão sistemática sobre coparentalidade realizada por Costa et al. (2017) sugere que a qualidade e o ajustamento conjugal anteriores ao nascimento da criança, o envolvimento parental e a coabitação entre pais e filhos, a qualificação da parentalidade do(a) parceiro(a), e o temperamento do(s) filho(s) atuam como preditores da qualidade da relação coparental. Além disso, foi consenso entre vários estudos coletados que a coparentalidade negativa associa-se a problemas de comportamento internalizantes e externalizantes na infância, conforme já constatado por outros pesquisadores (Mosmann et al., 2017; Machado \& Mosman, 2019). Oliveira e Crepaldi (2018) desenvolveram uma revisão integrativa acerca do envolvimento paterno após o divórcio. Os resultados demonstram que a qualidade da relação entre os ex-cônjuges e o envolvimento parental conjunto influenciam a relação entre o pai e a criança. O conflito coparental foi evidenciado como o fator que mais dificulta o envolvimento paterno após o rompimento da conjugalidade.

A criação dos filhos é uma das tarefas mais desafiadoras do ciclo vital (Pereira et al., 2015) e a vivência da separação pode interferir no exercício desse desafio (Lamela et al., 2010). As crianças são sensíveis às condições contextuais, de forma que a família representa uma fonte de influência fundamental para a saúde do desenvolvimento psicológico infantil. O período da primeira infância, especialmente até a faixa dos seis anos, é marcado pela aquisição de habilidades de relacionamento interpessoal, autorregulação emocional e resolução de problemas (Guttman et al., 2006). Nesse sentido, a influência positiva do sistema familiar é fundamental para o bem-estar ao longo de todo o ciclo de vida, dadas as evidências científicas que demonstram a dificuldade de reverter prejuízos psicológicos sofridos na primeira infância (Shonkoff et al., 2012).

Os construtos coparentalidade, envolvimento parental e práticas parentais são de grande relevância para o entendimento dos desafios enfrentados por famílias que passam pelo processo de separação conjugal. Com base nesse pressuposto, o objetivo desta revisão foi compreender como os fenômenos da coparentalidade, do envolvimento parental ou das práticas parentais influenciam na dinâmica de famílias biparentais. À medida que propõe uma sistematização de pesquisas empíricas, este estudo pretende contribuir para a reflexão acerca de estratégias de promoção de saúde psicológica de famílias divorciadas, por parte de profissionais que atendam a essa demanda, seja na área psicológica, social ou jurídica.

\section{Método}

A revisão sistemática da literatura consiste num método de sumarização de pesquisas prévias que acarreta produzir um estudo reflexivo, crítico e compreensivo, portanto vai além da mera descrição cronológica dos estudos (Zoltowski et al., 2014). O processo se deu em etapas: (a) busca das publicações científicas em base de dados com descritores preestabelecidos; (b) leitura dos títulos e dos resumos para seleção dos artigos relacionados aos objetivos; (c) recuperação e exame na íntegra dos artigos selecionados; e (d) síntese, análise e integração das contribuições dos estudos. Pontua-se que os termos "coparentalidade", "envolvimento parental" e "práticas parentais" não constaram na base de Terminologia em Psicologia da BVS-Psi (Biblioteca Virtual em Saúde - Psicologia), nem na base de Descritores em Ciências da Saúde (DeCS) da BVS (Biblioteca Virtual em Saúde), porém optou-se por utilizálos como termos de busca por considerá-los fundamentais para a compreensão e definição teórica dos fenômenos. 
A busca pelos artigos foi realizada entre outubro e dezembro de 2017, através do Portal Periódicos CAPES/MEC (com acesso institucional). Foram selecionadas as bases PsycINFO, Web of Science e Biblioteca Virtual em Saúde - Psicologia Brasil (BVSPsi). Na busca realizada na plataforma Web of science, optou-se apenas pela grande área temática das ciências sociais (Social Sciences Citation Index). As bases de dados internacionais PsycINFO e Web of Science possuem abrangência confiável (indexam muitas revistas ou periódicos), apresentam atualização regular, além de diversas funcionalidades que conferem maior assertividade na procura por artigos internacionais. A plataforma BVSPsi foi escolhida com intuito de contemplar uma busca entre o maior número possível de estudos nacionais da área da Psicologia.

Os descritores e termos de busca foram combinados das seguintes formas, em inglês e português: "coparentalidade e divórcio" ("coparenting and divorce"); "coparentalidade e separação conjugal" ("coparenting and marital separation"); "envolvimento parental e divórcio" ("parental involvement and divorce"); "envolvimento parental e separação conjugal" ("parental involvement and marital separation"); "práticas parentais e divórcio" ("parental practices and divorce"); "práticas parentais e separação conjugal" ("parental practices and marital separation").

Foram utilizados os seguintes critérios de inclusão: (a) tipo de publicação: somente artigos publicados em periódicos indexados (não incluindo teses, dissertações, nem outros tipos de publicações); (b) ano de publicação: artigos publicados entre os anos de 2012 e 2017. A escolha pelos artigos indexados representa o intuito de obter publicações que são avaliadas por pares, com maior controle da qualidade dos estudos, além de conteúdo mais acessível.

Os critérios de exclusão também foram previamente estabelecidos: (a) Idioma do artigo na íntegra: somente artigos publicados em português ou inglês (a base Psyclnfo não ofereceu a ferramenta de filtro por idioma, portanto o idioma foi inserido como critério de exclusão; (b) recorte metodológico: somente artigos de pesquisas empíricas, excluindo-se, por tanto, estudos de revisão de literatura, teóricos e relatos de validação de instrumentos/escalas; (c) Recorte temático: foram excluídos artigos que contemplavam os construtos de interesse, porém com foco em outras especificidades, como: avaliação de programas de intervenção, estudos com amostras clínicas/referidas, com famílias de crianças de desenvolvimento atípico e com famílias nucleares; (d) idade das crianças da amostra: foram excluídos os artigos que compreendiam amostras exclusivas de crianças com idade acima de 6 anos; e (e) tipo de acesso: artigos cujo texto na íntegra estivesse indisponível.

A ordem de análise do recorte temático dos artigos se deu primeiro pelos resumos, com caráter eliminatório. Nas situações geradoras de dúvida sobre a inclusão do manuscrito para análise, as investigadoras leram o texto integralmente e a decisão de inclusão ou exclusão se deu por consenso. Os artigos foram importados e organizados por meio do gerenciador de referências Zotero, e a revisão sistemática foi conduzida com base na adaptação da metodologia Preferred Reporting Items for Systematic Reviews and MetaAnalyses - PRISMA (Moher \& Tsertsvadze, 2006), que consiste em uma série de diretrizes e engloba uma lista de verificação de itens sobre os principais pontos de análise do material coletado.

Os dados foram analisados, inicialmente, por meio das características gerais dos artigos: ano de publicação, amostra, país onde foram realizados, delineamento metodológico e instrumentos adotados pelos pesquisadores. Posteriormente, os resultados dos estudos 
foram discutidos criticamente e avaliados no que diz respeito à influência das variáveis em pauta da dinâmica das famílias divorciadas, buscando contemplar implicações para os campos teórico e prático.

\section{Resultados}

Conforme evidenciado na Figura 1 (apresentada logo após a sessão de referências), foram encontradas 404 publicações, das quais 160 foram excluídas por duplicidade, restando 244 resumos lidos. Na amostra final, oito estudos abordaram o construto envolvimento parental e nove trataram do construto coparentalidade. Após a leitura dos artigos na íntegra, todas as pesquisas sobre práticas parentais anteriormente identificadas $(n=3)$ foram eliminadas por utilizar amostras de pais de crianças com 6 anos ou mais, ou seja, fora do escopo delimitado.

Na Tabela 1 os artigos de 1 a 8 tratam do envolvimento parental e os seguintes, de 9 a 17, são sobre coparentalidade. Quanto aos anos de publicação, houve bastante variabilidade, com destaque para os anos de 2014 e 2016, ambos com cinco publicações. Em relação aos países onde foram conduzidas as pesquisas, nove foram realizadas nos Estados Unidos, duas em Portugal e cada uma das demais em diferentes países.

Conforme apresentado na Tabela 2, dentre as oito pesquisas sobre envolvimento parental, apenas uma teve amostra exclusiva de homens e outra de díades parentais, e três estudos utilizaram exclusivamente mulheres. Amostras mistas, ou seja, de pais e mães que não eram díades parentais, foram representadas por três estudos, porém, mesmo nesses casos, houve número maior de mães. Já em relação aos nove estudos coletados sobre coparentalidade, três utilizaram relatos de pais e de mães (não díades) e nas seis pesquisas restantes somente mães foram respondentes.

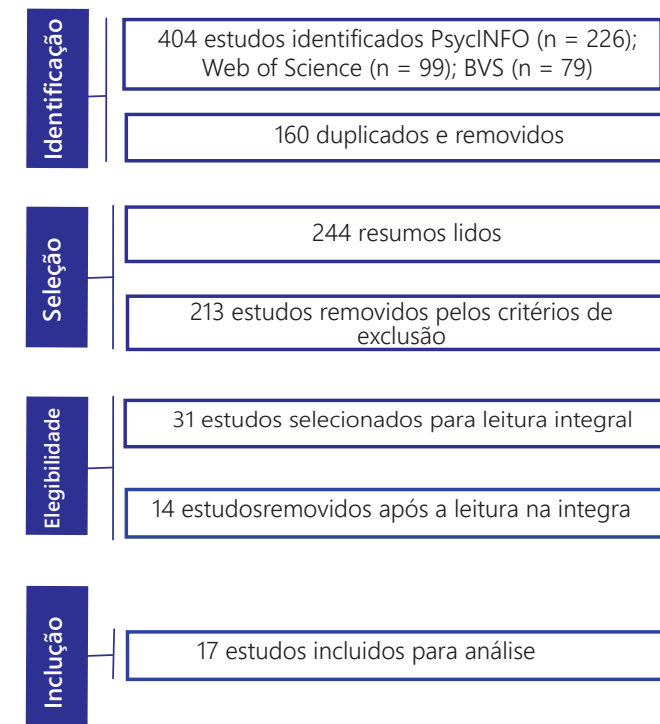

(i) Artigos não publicados nos idiomas inglês ou português ( $n=$ 13); (ii) Revisões de literatura e artigos teóricos ( $n=33$ ); (iii) Estudos que não contemplavam os construtos coparentalidade envolvimento parental e/ou prácticas parentais ( $n=57$ ); (iv) Artigos com foco em programas de intervenção, amostras clínicas e familias nucleares $(n=80)$; (v) Estudos que não compreendiam amostras de crianças menores de 6 anos $(n=21)$; (vi) Artigos que se tratam de validação de escalas/instrumento $(n=9)$.

(i) Estudos que não contemplavam os construtos coparentalidade, envolvimento parental e/ou prácticas parentais $(n=3)$; (ii) Revisões de literatura e artigos teóricos $(n=1)$; (iii) Estudos que não compreendiam amostras de crianças menores de 6 anos $(n=6)$; (vi) Artigos com foco em programas de intertvenção, amostras clínicas e famílias nucleares $(n=4)$.

Envolvimiento parental nocontexto das familias binucleares $(\mathrm{n}=8)$. Coparentalidade no contexto das familias binucleares $(n=9)$. Prácticas parentais no contexto das familias

binucleares $(n=0)$.

Figura 1. Fluxograma de identificação e seleção dos artigos. 
Tabela 1

Caracterização geral dos estudos

\begin{tabular}{|c|c|c|c|c|}
\hline Id. & Título & Autores & Ano & País \\
\hline 1 & $\begin{array}{l}\text { Predictors of Involvement and Warmth of Custodial Fathers } \\
\text { in Israel: Comparison with Married and Noncustodial } \\
\text { Divorced Fathers }\end{array}$ & $\begin{array}{l}\text { Finzi-Dottan e } \\
\text { Cohen }\end{array}$ & 2016 & Israel \\
\hline 2 & $\begin{array}{l}\text { Parenting Style, Parental Adjustment, and Co-Parental Conflict: } \\
\text { Differential Predictors of Child Psychosocial Adjustment } \\
\text { Following Divorce }\end{array}$ & $\begin{array}{l}\text { Stallman e } \\
\text { Ohan }\end{array}$ & 2016 & Austrália \\
\hline 3 & $\begin{array}{l}\text { Nonresident Father Involvement with Children and Divorced } \\
\text { Women's Likelihood of Remarriage }\end{array}$ & $\begin{array}{l}\text { McNamee, } \\
\text { Amato e King }\end{array}$ & 2014 & EUA \\
\hline 4 & $\begin{array}{l}\text { Parents apart: differences between unmarried and divorcing } \\
\text { parents in separated families }\end{array}$ & Waller e Emory & 2014 & EUA \\
\hline 5 & $\begin{array}{l}\text { Do nonresident fathers compensate for a lack of household } \\
\text { resources? The associations between paternal involvement and } \\
\text { children's cognitive and educational assessments in the UK }\end{array}$ & $\begin{array}{l}\text { Tanskanen e } \\
\text { Erola }\end{array}$ & 2017 & $\begin{array}{l}\text { Reino } \\
\text { Unido }\end{array}$ \\
\hline 6 & $\begin{array}{l}\text { Father Contact Following Union Dissolution for Low- Income } \\
\text { Children in Urban South Africa }\end{array}$ & $\begin{array}{l}\text { Madhavan, } \\
\text { Richter e Norris }\end{array}$ & 2016 & $\begin{array}{l}\text { África do } \\
\text { Sul }\end{array}$ \\
\hline 7 & $\begin{array}{l}\text { Non-resident parent-child contact after marital dissolution and } \\
\text { parental repatterning: Evidence from Italy }\end{array}$ & $\begin{array}{l}\text { Meggiolaro e } \\
\text { Ongaro }\end{array}$ & 2015 & Itália \\
\hline 8 & $\begin{array}{l}\text { Who Is the Residential Parent? Understanding Discrepancies in } \\
\text { Unmarried Parents' Reports }\end{array}$ & Waller e Jones & 2014 & EUA \\
\hline 9 & $\begin{array}{l}\text { Perfis de Vinculação, Coparentalidade e Ajustamento Familiar em } \\
\text { Pais Recém-Divorciados: Diferenças no Ajustamento Psicológico }\end{array}$ & $\begin{array}{l}\text { Lamela, } \\
\text { Figueiredo e } \\
\text { Bastos }\end{array}$ & 2013 & Portugal \\
\hline 10 & $\begin{array}{l}\text { Typologies of Post-divorce Coparenting and Parental Well-Being, } \\
\text { Parenting Quality and Children's Psychological Adjustment }\end{array}$ & $\begin{array}{l}\text { Lamela, } \\
\text { Figueiredo, } \\
\text { Bastos e } \\
\text { Feinberg }\end{array}$ & 2016 & Portugal \\
\hline 11 & $\begin{array}{l}\text { Implications of New Marriages and Children for Coparenting in } \\
\text { Nonresident Father Families }\end{array}$ & McGene e King & 2012 & EUA \\
\hline 12 & $\begin{array}{l}\text { Perceived Barriers to Postdivorce Coparenting: Differences } \\
\text { Between Men and Women and Associations with } \\
\text { Coparenting Behaviors }\end{array}$ & $\begin{array}{l}\text { Russell, } \\
\text { Beckmeyer, } \\
\text { Coleman e } \\
\text { Ganong }\end{array}$ & 2016 & EUA \\
\hline 13 & Postdivorce Coparenting Typologies and Children's Adjustment & $\begin{array}{l}\text { Beckmeyer, } \\
\text { Coleman e } \\
\text { Ganong }\end{array}$ & 2014 & EUA \\
\hline 14 & $\begin{array}{l}\text { Coparenting and Children's Adjustment to Divorce: The Role of } \\
\text { Geographical Distance from Fathers }\end{array}$ & Viry & 2014 & Suíça \\
\hline 15 & Factors Linked with Coparenting Support and Conflict After Divorce & $\begin{array}{l}\text { Petren, Ferraro, } \\
\text { Davis e Pasley }\end{array}$ & 2017 & EUA \\
\hline 16 & $\begin{array}{l}\text { Coparenting and Nonresident Fathers' Monetary Contributions } \\
\text { to Their Children }\end{array}$ & Goldberg & 2015 & EUA \\
\hline 17 & $\begin{array}{l}\text { Patterns and Predictors of Coparenting After Unmarried } \\
\text { Parents Part }\end{array}$ & $\begin{array}{l}\text { Goldberg e } \\
\text { Carlson }\end{array}$ & 2015 & EUA \\
\hline
\end{tabular}

Nota. Os estudos foram rotulados com um código (Id.) a fim de facilitar a identificação nas tabelas. 
Tabela 2

Características das amostras e instrumentos utilizados nos estudos

\begin{tabular}{|c|c|c|}
\hline Id. & Amostra & Instrumentos utilizados nos estudos \\
\hline 1 & $\begin{array}{l}545 \text { pais (homens) com filho(s) } \\
\text { menor(es) de } 18 \text { anos ( } 218 \text { que } \\
\text { detinham a custódia da criança, } 222 \\
\text { casados e } 105 \text { divorciados sem a } \\
\text { custódia da criança). }\end{array}$ & $\begin{array}{l}\text { - Envolvimento parental: Instrument of Father Involvement (Hawkins, } \\
\text { et al., 2002). } \\
\text { - Autoeficácia parental: Parenting Sense of Competence (Johnston, } \\
\text { \& Mash, 1989). } \\
\text { - Calor parental: PARQ-Short (Rohner, Khaleque, \& Cournoyer, 2005). } \\
\text { - Coordenação coparental: subescala derivada da Relationship } \\
\text { between Former Spouses Scale (Goldsmith, 1980). }\end{array}$ \\
\hline 2 & $\begin{array}{l}96 \text { mães e } 13 \text { pais com filho(s) entre } 4 \text { e } \\
17 \text { anos, que não eram díades parentais. }\end{array}$ & $\begin{array}{l}\text { - Estilo parental: Parenting Scale (Arnold, et al., 1993); } \\
\text { - Conflito coparental: Acrimony Scale (Shaw \& Emery, 1987). }\end{array}$ \\
\hline 3 & $\begin{array}{l}882 \text { mães, com filho(s) menor(es) de } 18 \\
\text { anos residentes com a mãe. }\end{array}$ & $\begin{array}{l}\text { - Envolvimento do pai não-residente: (a) frequência de contato e } \\
\text { (b) pagamento de apoio à criança. }\end{array}$ \\
\hline 4 & $\begin{array}{l}1.630 \text { mães e } 1.047 \text { pais com filho(s) } \\
\text { de } 1,3 \text { ou } 5 \text { anos, que não eram } \\
\text { díades parentais. }\end{array}$ & $\begin{array}{l}\text { - Qualidade do relacionamento com o pai: escala likert de } 1 \\
\text { (ruim) a } 5 \text { (excelente). }\end{array}$ \\
\hline 5 & $\begin{array}{l}3445 \text { mães, com a(s) criança(s) de } \\
\text { idade média de } 11 \text { anos, residentes } \\
\text { com a mãe. }\end{array}$ & $\begin{array}{l}\text { - Cooperação parental: escala likert de } 1 \text { (nunca é verdadeiro) a } \\
4 \text { (sempre é verdadeiro). }\end{array}$ \\
\hline 6 & $\begin{array}{l}828 \text { mães, com filho(s) menor(es) de } 11 \\
\text { anos, residentes com a mãe. }\end{array}$ & $\begin{array}{l}\text { - Contato parental: relato dos pais e das mães sobre a quantidade } \\
\text { e a qualidade do contato com a(s) criança(s). }\end{array}$ \\
\hline 7 & $\begin{array}{l}1214 \text { pais com filho(s) menor(es) de } \\
17 \text { anos, sendo } 1.079 \text { com criança(s) } \\
\text { residentes com a mãe e } 135 \text { com } \\
\text { criança(s) residentes com o pai. }\end{array}$ & $\begin{array}{l}\text { - Envolvimento parental: frequência de contato pessoal e por } \\
\text { telefone: escala likert de } 1 \text { (todos os dias) a } 6 \text { (nunca). }\end{array}$ \\
\hline 8 & $\begin{array}{l}1156 \text { díades parentais, com filho(s) de } \\
1,3 \text { ou } 5 \text { anos. }\end{array}$ & $\begin{array}{l}\text { - Envolvimento parental: variável categórica para distinguir } \\
\text { os pais que passam noites com a mãe e o filho de pais que } \\
\text { passavam noites apenas com a criança; e qualidade da relação } \\
\text { com a criança: escala likert de (1) pobre a (5) excelente. }\end{array}$ \\
\hline 9 & $\begin{array}{l}53 \text { mães e } 28 \text { pais com filho(s) } \\
\text { menor(es) de } 5 \text { anos, que não eram } \\
\text { díades parentais. }\end{array}$ & $\begin{array}{l}\text { - Coparentalidade: Parenting Alliance Measure (Abidin \& } \\
\text { Konold, 1999). }\end{array}$ \\
\hline 10 & $\begin{array}{l}244 \text { mães e } 80 \text { pais com filho(s) } \\
\text { entre } 4 \text { e } 16 \text { anos, que não eram } \\
\text { díades parentais. }\end{array}$ & $\begin{array}{l}\text { - Coparentalidade: Coparenting Relationship Scale (Feinberg } \\
\text { et al., 2012). }\end{array}$ \\
\hline 11 & $\begin{array}{l}628 \text { mães, com filho(s) entre } 2 \text { e } 14 \\
\text { anos, residentes com a mãe. }\end{array}$ & $\begin{array}{l}\text { - Cooperação coparental: dois itens, que mensuravam (1) a } \\
\text { influência que o pai teve nas principais decisões de criação dos } \\
\text { filhos e (2) com que frequência a mãe e o pai discutiam sobre } \\
\text { a criança. }\end{array}$ \\
\hline 12 & $\begin{array}{l}180 \text { mães e } 111 \text { pais, com filho(s) } \\
\text { entre } 3 \text { e } 18 \text { anos, que não eram } \\
\text { díades parentais. }\end{array}$ & $\begin{array}{l}\text { - Barreiras à coparentalidade pós-divórcio: } 13 \text { itens desenvolvidos } \\
\text { para o estudo. Resultaram em três subescalas: financeira legal, } \\
\text { temporal logística e aptidão parental; }\end{array}$ \\
\hline
\end{tabular}

Continue... 
Tabela 2

Características das amostras e instrumentos utilizados nos estudos

\begin{tabular}{|c|c|c|}
\hline Id. & Amostra & Instrumentos utilizados nos estudos \\
\hline 12 & $\begin{array}{l}180 \text { mães e } 111 \text { pais, } \\
\text { com filho(s) entre } 3 \text { e } \\
18 \text { anos, que não eram } \\
\text { díades parentais. }\end{array}$ & $\begin{array}{l}\text { - Comportamentos de coparentalidade pós-divórcio: três dimensões: quantidade } \\
\text { de comunicação coparental: Coparental Interaction Scale (Ahrons, 1981); cooperação } \\
\text { cooperantal; e conflito coparental com o seu ex-cônjuge: subescalas do Coparenting } \\
\text { Questionnaire (Margolin et al., 2001). }\end{array}$ \\
\hline 13 & $\begin{array}{l}270 \text { mães, com filho(s) } \\
\text { entre } 3 \text { e } 19 \text { anos. }\end{array}$ & $\begin{array}{l}\text { - Cooperação coparental: subescala de seis itens do Coparenting Questionnaire } \\
\text { (Margolin et al., 2001). } \\
\text { - Coparentalidade conflituosa: subescala conflito de quatro itens do Coparenting } \\
\text { Questionnaire (Margolin et al., 2001). } \\
\text { - Comunicação coparental: Coparental Interaction Scale (Ahrons, 1981). }\end{array}$ \\
\hline 14 & $\begin{array}{l}144 \text { mães com filho(s) } \\
\text { entre } 5 \text { e } 14 \text { anos. }\end{array}$ & $\begin{array}{l}\text { - Proximidade residencial dos pais: a distância foi recodificada em três categorias. } \\
\text { - Frequência de contato face-a-face e indiretos (telefone, e-mail): escala likert de (1) } \\
\text { todos os dias a (5) nunca ou quase nunca. } \\
\text { - Coesão coparental: itens foram baseados na interação das mães com seus ex- } \\
\text { parceiros e filhos quando todos três estavam fisicamente. }\end{array}$ \\
\hline 15 & $\begin{array}{l}176 \text { mães, com filho(s) } \\
\text { menor(es) de } 18 \text { anos. }\end{array}$ & $\begin{array}{l}\text { - Apoio à coparentalidade, conflito aberto e conflito encoberto: seis itens da } \\
\text { Quality of Coparental Communication Scale (Ahrons, 1981) e nove itens da } \\
\text { Coparental Competition and Conflict (Buehler \& Trotter, 1990). } \\
\text { - Importância do envolvimento do pai para o desenvolvimento da criança: cinco } \\
\text { itens da Parental Involvement Scale (Ahrons \& Miller, 1993), três itens do Praise } \\
\text { and Affection subscale of the Inventory of Father Involvement Scale (Hawkins } \\
\text { et al., 2002) e cinco itens desenvolvidos para a pesquisa, a fim de avaliar a } \\
\text { importância de prover monetariamente a criança. }\end{array}$ \\
\hline 16 & $\begin{array}{l}1.752 \text { mães com filho(s) } \\
\text { menor(es) de } 9 \text { anos. }\end{array}$ & $\begin{array}{l}\text { - Contribuições monetárias dos pais não residentes para o filho: respostas das } \\
\text { mães a uma série de perguntas formuladas para o estudo. } \\
\text { - Relação coparental: cinco itens elaborados para o estudo mais amplo: } \\
\text { frequência de comportamentos e avaliação de elementos-chave de apoio } \\
\text { coparental, incluindo comunicação, confiança e respeito mútuo. }\end{array}$ \\
\hline 17 & $\begin{array}{l}1.193 \text { mães com filho(s) } \\
\text { menor(es) de } 9 \text { anos. }\end{array}$ & $\begin{array}{l}\text { - Relação coparental: cinco itens elaborados para o estudo: frequência de } \\
\text { comportamentos e avaliação de elementos-chave de apoio coparental, } \\
\text { incluindo comunicação, confiança e respeito mútuo. }\end{array}$ \\
\hline
\end{tabular}

O envolvimento parental foi tratado pelos autores a partir de diferentes concepções, incluindo calor parental (manifestação de aceitação dos pais, carinho, cuidado, conforto, preocupação, nutrição, apoio e amor); autoeficácia parental (crença em relação à própria capacidade de desempenhar sua função como pais (Finzi-Dottan \& Cohen, 2016); e qualidade do relacionamento dos pais com a criança (Waller \& Emory, 2014). Um dos artigos (Stallman \& Ohan, 2016) trabalhou com o conceito de estilo parental (Arnold et al., 1993), que compõe um conjunto de atitudes relativamente estáveis adotadas pelos pais, no que diz respeito às questões de poder, hierarquia e apoio emocional na relação com os filhos (Böing \& Crepaldi, 2016). 
Consequentemente, o construto envolvimento parental foi mensurado de formas diversificadas. Metade das pesquisas (quatro) utilizaram como medida do envolvimento parental a frequência de contato do pai ou da mãe não residente com a criança, sendo que dois dos estudos incluíram o apoio financeiro ao(s) filho(s). Foram identificadas duas escalas validadas de avaliação do envolvimento parental: Escala de Envolvimento Parental ou Parental Involvement Scale (Ahrons \& Miller, 1993); e Instrumento de Envolvimento do Pai ou Instrument of Father Involvement (Hawkins et al., 2002), sendo que esse último foi desenvolvido especificamente para avaliar o envolvimento paterno.

As pesquisas sobre coparentalidade abordaram aspectos como cooperação coparental (frequência com que os pais discutem sobre educação dos filhos e o quanto atribuem influência do ex-cônjuge nas decisões sobre a(s) criança(s); coesão coparental (frequência com que os pais promoviam relação positiva pai/mãe-criança tanto em comportamentos públicos/externos, quanto em comportamentos privados); relação coparental (frequência de comportamentos e elementos do suporte coparental, incluindo comunicação, confiança e respeito mútuo no papel parental); e barreiras à coparentalidade pós-divórcio (barreira financeira legal, temporal logística e de aptidão parental).

Os instrumentos para mensurar a coparentalidade também foram bastante diversificados. Uma pesquisa empregou a Medida da Aliança Parental ou Parenting Alliance Measure (Abidin \& Konold, 1999), outro estudo utilizou ou Escala de Relação Coparental ou Coparenting Relationship Scale (Feinberg et al., 2012). O Questionário de Coparentalidade ou Coparenting Questionnaire (Margolin et al., 2001) foi usado em duas investigações, assim como a Escala de Interação Coparental ou Quality of Coparental Communication Scale (Ahrons, 1981). Para avaliar a coordenação coparental, foi empregada a Escala de Relacionamento entre Ex-Cônjuges ou Relationship between Former Spouses Scale (Goldsmith, 1980); e para mensurar o conflito coparental, utilizouse a Escala de Acrimonia ou Acrimony Scale (Shaw \& Emery, 1987). Quatro das nove pesquisas sobre coparentalidade utilizaram itens desenvolvidos especificamente para os estudos em questão.

Complementando as informações expostas nas tabelas, é importante pontuar que sete estudos compilados tiveram delineamento metodológico longitudinal e 10 foram transversais. As análises dos dados, em todas as publicações, empregaram procedimentos de estatística descritiva (descrição de médias e desvios-padrão) e inferencial, de acordo com os problemas de pesquisa de cada artigo (testes $T$, análise de variância e covariância, análise fatorial confirmatória e exploratória, testes de correlação, regressões logísticas e lineares múltiplas, análise multivariada, testes de modelos de mediação múltipla e modelagem de equações estruturais). Por fim, a sistematização dos objetivos e principais resultados dos estudos coletados são apresentados na Tabela 3. 
Tabela 3

Objetivos e principais resultados dos estudos

\begin{tabular}{lll}
\hline Id. Objetivos & \multicolumn{1}{c}{ Principais resultados } \\
\hline 1 Comparar os níveis e preditores de & Os pais divorciados que detinham a custódia da criança \\
calor e envolvimento parental entre & apresentaram níveis mais elevados de envolvimento parental, \\
três grupos de pais: 1. Divorciados & se comparados aos pais casados ou que não tinha a custódia \\
que detinham a custódia da criança; & do filho. Especificamente para esses pais, a coparentalidade \\
2. Casados; e 3. Divorciados que não & associou-se positivamente ao envolvimento parental. O \\
detinham a custódia da criança. & tipo de cuidado recebido pelos pais de seus próprios pais, \\
& bem como a autoeficácia paterna, foram preditores do \\
& envolvimento parental.
\end{tabular}

2 Examinar se o ajustamento parental (angústia e raiva), o conflito coparental e o estilo parental (permissividade e excesso de reatividade) previam o ajustamento infantil (comportamentos internalizantes e externalizantes da criança), após o divórcio dos pais.

3 Investigar se o envolvimento parental de pais não residentes afetou a possibilidade de recasamento da mãe divorciada e o apoio financeiro do pai em relaçãoà criança.

4 Examinar e comparar as circunstâncias dos pais solteiros e dos que já foram casados com a mãe da criança, mas vivem separados, cinco anos depois do nascimento do filho.

5 Identificar se o envolvimento parental de pais residentes e não residentes com a criança após o divórcio estaria associado a maiores realizações das crianças em termos cognitivos e educacionais, e ao nível educacional e de renda da família.

6 Analisar o envolvimento de pais negros não residentes com seus filhos após a dissolução conjugal, examinando os padrões de contato do pai em relação ao estágio de vida da criança no momento da dissolução conjugal, da entrada da mãe em um novo relacionamento e das possíveis mudanças no padrão de contato do

Observou-se que a falta de ajustamento mental dos pais divorciados (ou seja, o aumento da angústia e da raiva de ambos os pais), o alto nível de conflito coparental e o estilo parental permissivo foram fatores preditivos para o aumento dos problemas emocionais e comportamentais das crianças.

O recasamento da mãe divorciada foi positivamente associado ao envolvimento parental do pai não residente, mas não se associou ao recebimento de apoio financeiro por parte do pai à criança.

Foi constatado maior nível de envolvimento parental (contato e qualidade do relacionamento com a criança, e cooperação parental) entre os pais divorciados que em algum momento tiveram proximidade tanto com a ex-esposa quanto com o filho, se comparados àqueles pais que nunca foram casados com a mãe da criança.

Observou-se associação positiva entre envolvimento parental e realizações do filho; e negativa entre envolvimento parental e maior nível educacional/de renda entre os pais que não residiam com a criança. pai ao longo do tempo.

Continue. 
Tabela 3

Objetivos e principais resultados dos estudos

\begin{tabular}{ll}
\hline ld. & Objetivos \\
\hline 7 & Analisar como o contato dos pais e mães \\
não residentes com seus filhos variava \\
de acordo com uma nova união do ex- \\
cônjuge (residente ou não-residente) e \\
investigar se o relacionamento entre o \\
contato parental diferia de acordo com \\
o gênero do pai não residente. \\
8 Realizar uma análise comparativa dos \\
relatórios de pais e mães divorciados \\
(decorrentes do Fragile Families and \\
Child Wellbeing) a respeito da situação \\
de moradia dos filhos, ou seja, buscando \\
identificar se havia discrepância no relato \\
de pais e mães referentes ao lugar onde \\
os filhos passavam a maior parte do \\
tempo (na casa do pai ou da mãe).
\end{tabular}

Principais resultados

O recasamento dos pais (considerando pais e mães) associouse positivamente ao menor contato entre pais não residentes e seus filhos somente no caso de pais (homens); no caso de mães não residentes, contrariamente, uma nova união conjugal se correlacionou com o aumento do contato com a criança.

Observou-se que a falta de rede de apoio por parte de ambos os pais foi preditiva para a menor acessibilidade ao filho. Foi possível, ainda, identificar dois tipos diferentes de arranjos familiares, que poderiam contribuir para a discrepância dos dados dos relatórios: alguns pais viviam com a mãe (ex-parceira) em tempo parcial e outros passavam noites especificamente com o filho, sem relacionar-se com a mãe. Mais de um terço dos pais discordavam a respeito de "com quem seu filho vivia" e que a discrepância nos relatórios era muito mais provável quando os pais passavam algumas noites com a mãe (um indicador de coabitação em tempo parcial).

9 Testar se perfis de regulação individualdiádico-sistêmico após o divórcio poderiam seridentificados e confirmados empiricamente, e examinar diferenças ao nível do ajustamento psicológico e de variáveis sociodemográficas dos pais recém-divorciados.

10 Identificar os perfis de coparentalidade após o divórcio e examinar a relação desses perfis com níveis de bem-estar dos pais, práticas parentais e problemas psicológicos das crianças.

11 Investigar a importância dos recasamentos e novos filhos dos pais e mães residentes para os níveis de cooperação coparental e testar se as mudanças na coparentalidade estavam ligadas às mudanças nos estatutos matrimoniais ou de fertilidade dos pais.

Três padrões de regulação foram identificados: reguladoseguro (RS), desregulado-ansioso (DA) e desreguladoevitante (DE). O grupo RS mostrou níveis mais elevados de segurança na vinculação, maior qualidade na coparentalidade e no ajustamento familiar, se comparados aos outros dois grupos.

O grupo de pais com níveis altos de conflito coparental exibiu pontuações significativamente menores de satisfação de vida, bem como graus significativamente maiores de afeto negativo relacionado ao divórcio e de paternidade inconsistente. $O$ grupo com maior coparentalidade cooperativa relatou níveis mais elevados de funcionamento familiar positivo e menos problemas de externalização e internalização em seus filhos.

As mudanças na estrutura familiar (recasamento ou novo filho) do pai mostraram-se mais importantes para a cooperação coparental do que para as mudanças na estrutura familiar da mãe. A distância da casa do pai (homem) foi significativa, com uma distância crescente associada com uma diminuição na coparentalidade ao longo do tempo.

Continue.. 
Tabela 3

Objetivos e principais resultados dos estudos

\begin{tabular}{|c|c|c|}
\hline Id. & Objetivos & Principais resultados \\
\hline 12 & $\begin{array}{l}\text { Comparar as percepções de pais } \\
\text { e mães sobre como e quanto } \\
\text { as barreiras legais-financeiras, } \\
\text { tempo-logística e as barreiras de } \\
\text { aptidão parental influenciaram a } \\
\text { coparentalidade pós-divórcio. }\end{array}$ & $\begin{array}{l}\text { Os homens perceberam maiores barreiras legais-financeiras e } \\
\text { de tempo-logística na coparentalidade pós-divórcio do que as } \\
\text { mulheres e relataram relações menos positivas de coparentalidade. } \\
\text { Não houve diferenças de gênero para as barreiras de aptidão } \\
\text { parental. As mulheres tendiam a se comunicar menos com } \\
\text { os homens quando percebiam mais preocupações jurídico- } \\
\text { financeiras relacionadas ao divórcio. }\end{array}$ \\
\hline 13 & $\begin{array}{l}\text { Classificar a percepção de pais } \\
\text { divorciados sobre o relacionamento } \\
\text { com o ex-cônjuge e testar se as } \\
\text { percepções dos pais acerca do } \\
\text { ajustamento dos filhos após o } \\
\text { divórcio diferiam com base nas } \\
\text { suas percepções do relacionamento } \\
\text { coparental pós-divórcio. }\end{array}$ & $\begin{array}{l}\text { A coparentalidade conflituosa foi positivamente associada à maior } \\
\text { percepção dos pais em relação a problemas de comportamento de } \\
\text { externalização e internalização dos filhos, bem como negativamente } \\
\text { associada com habilidades sociais das crianças. A comunicação } \\
\text { coparental foi associada negativamente ao comportamento de } \\
\text { internalização das crianças. Aproximadamente, } 31 \% \text { da amostra } \\
\text { apresentou coparentalidade cooperativa, } 45 \% \text { coparentalidade } \\
\text { moderadamente engajada e } 24 \% \text { coparentalidade conflituosa. }\end{array}$ \\
\hline 14 & $\begin{array}{l}\text { Explorar como a distância entre } \\
\text { as casas dos pais (homens) } \\
\text { relacionava-se à promoção } \\
\text { materna do relacionamento } \\
\text { pai-filhos (coesão coparental) } \\
\text { e aos desfechos emocionais e } \\
\text { comportamentais das crianças. }\end{array}$ & $\begin{array}{l}\text { Tanto a coparentalidade como a proximidade dos pais tiveram } \\
\text { efeitos positivos e independentes no bem-estar emocional e } \\
\text { comportamental das crianças. Crianças com pais vivendo nas } \\
\text { proximidades tiveram probabilidade significativamente menor } \\
\text { de ter graves dificuldades comportamentais de hiperatividade } \\
\text { e probabilidade significativamente maior de comportamento } \\
\text { pró-social. A coesão coparental previu níveis significativamente } \\
\text { mais baixos de dificuldades comportamentais, de hiperatividade } \\
\text { e com os pares. Nem a frequência de contato pai-filho nem } \\
\text { o arranjo de custódia infantil influenciaram significativamente } \\
\text { as dificuldades das crianças. Os pais (homens) foram mais } \\
\text { propensos a ligar ou enviar por e-mail aos filhos quando } \\
\text { facilitavam o envolvimento paterno. }\end{array}$ \\
\hline 15 & $\begin{array}{l}\text { Examinar a relação entre } \\
\text { os indicadores pessoais e } \\
\text { interpessoais do ajustamento } \\
\text { pós-divórcio e as dimensões da } \\
\text { coparentalidade (suporte, conflito } \\
\text { aberto e conflito encoberto). }\end{array}$ & $\begin{array}{l}\text { Satisfação com o divórcio, satisfação com a parentalidade do } \\
\text { pai e a importância do pai foram positivamente relacionados } \\
\text { com o suporte coparental. O conflito coparental foi relacionado } \\
\text { negativamente à satisfação com o divórcio, e a satisfação com a } \\
\text { parentalidade do pai foi positivamente associada ao estresse. }\end{array}$ \\
\hline 16 & $\begin{array}{l}\text { Analisar como a coparentalidade } \\
\text { - o grau em que os pais (homens) } \\
\text { são mutuamente solidários e } \\
\text { cooperativos na criação de seus filhos } \\
\text { — estava relacionada às contribuições } \\
\text { monetárias dos pais não residentes. }\end{array}$ & $\begin{array}{l}\text { Níveis mais elevados de coparentalidade foram associados a } \\
\text { maiores probabilidades de pagamento dos pais não residentes. } \\
\text { Porém, o maior preditor de contribuição foi o emprego do pai. }\end{array}$ \\
\hline
\end{tabular}

Continue... 
Tabela 3

Objetivos e principais resultados dos estudos

\begin{tabular}{lll}
\hline Id. Objetivos & \multicolumn{1}{c}{ Principais resultados } \\
\hline 17 Descrever os padrões de coparentalidade & A qualidade do relacionamento romântico dos pais, quando \\
ao longo de seis anos após o término & eles ainda estavam juntos, foi um preditor forte e consistente \\
de uma relação conjugal e identificar as & de sua trajetória de coparentalidade subsequente. Casais \\
características individuais e interpessoais & em que a mãe começou um relacionamento com um \\
associadas com a coparentalidade ao & novo parceiro eram mais propensos a estar em um nível \\
longo do tempo. & consistentemente baixo de coparentalidade. No entanto, \\
& a fertilidade multiparceira de mães foi positivamente \\
& associada com as mães que tiveram um filho com outro \\
& parceiro eram mais propensas a estar no grupo de \\
& coparentalidade consistentemente elevado do que declinar \\
& de alta para baixa ou ser consistentemente baixo. Por outro \\
& lado, quando os homens tinham uma criança com outro \\
& parceiro, os pais eram menos propensos a estar no grupo \\
& de alta qualidade coparental.
\end{tabular}

\section{Discussão}

O primeiro ponto a ser observado nesta revisão refere-se a ausência de estudos sobre práticas parentais dentro dos critérios de busca estabelecidos, o que acabou por atender apenas parte do objetivo proposto, gerando uma lacuna que precisa ser discutida. $\mathrm{O}$ conjunto de comportamentos e atitudes que constituem a parentalidade recebe diferentes designações na literatura científica, como, por exemplo: práticas parentais, práticas educativas, práticas de cuidados, estilos parentais e cuidados parentais (Kobarg et al., 2010). Considerando que a finalidade deste estudo era trabalhar com amostras de famílias com crianças na primeira infância, optou-se por empregar a expressão "práticas parentais", já que esse termo vem sendo utilizado nos estudos com filhos de até seis anos de idade, e quando se fala em "práticas educativas", há predomínio de pesquisas com famílias de adolescentes (Macarini et al., 2010). Além disso, as constatações da revisão realizada por Macarini et al. (2010) parecem ainda ser válidas para a presente pesquisa, dado o crescimento significativo de investigações sobre práticas educativas nos últimos anos, possivelmente devido à emergência de novas escalas mais condizentes com esse construto.

Nesse mesmo sentido, cabe destacar o emprego de uma ampla variedade de conceitos e instrumentos que foram tratados pelos pesquisadores dentro das concepções de envolvimento parental e coparentalidade. A análise dessa diversidade remete a uma reflexão acerca da falta de delimitação clara das definições, o que tende a dificultar tanto o processo de operacionalização quanto de uma compreensão sistematizada acerca das temáticas. Parte disso deve-se à própria trajetória de exploração científica tanto da coparentalidade quanto do envolvimento parental, já que ambos os fenômenos emergiram enquanto construtos psicológicos associados a estudos das relações familiares após processos de divórcio/separação conjugal (Lamela, Figueiredo et al., 2010; Gomes et al., 2014). A falta de pesquisas brasileiras dentro do escopo e do período delimitados por esta pesquisa é um ponto a ser destacado, e, possivelmente, deve-se ao mesmo motivo, pois as temáticas da coparentalidade e do envolvimento parental são mais recentes na literatura, se comparadas à práticas parentais e aos estilos parentais (Gomes et al., 2014; Flouri et al., 2016). 
A partir da década de 1990, a coparentalidade começou a ser alvo de estudos em famílias nucleares (Belsky et al., 1995), sendo que somente nas duas últimas décadas o conceito passou a ser explorado em diferentes configurações familiares (Lamela et al., 2010). Já quando se trata do envolvimento parental, a ideia inicial dos pesquisadores, anteriormente à década de 1990, originou-se em função do aumento no número de divórcios, com o objetivo de avaliar especificamente o envolvimento do pai (homem) não-residente na vida dos filhos após a separação conjugal. A estrutura conceitual do envolvimento parental proposta por Lamb et al. (1985) é a mais empregada em pesquisas empíricas, com o objetivo de investigar o envolvimento de ambos os progenitores com a criança, sob a denominação de envolvimento parental (Flouri et al., 2016).

Em revisão de literatura, Gomes et al. (2014) encontraram 15 instrumentos de mensuração do envolvimento paterno, porém boa parte dos instrumentos compilados também são direcionados também à figura da mãe, ou seja, tratam-se do envolvimento parental. Além disso, nem todas as descrições das escalas forneciam informações objetivas referentes à definição, à validade e à confiabilidade. O mesmo ocorreu na presente revisão, pois nem todos os autores apontaram os índices de consistência interna das escalas empregadas e dos questionários elaborados/aplicados. Essa ausência de padronização, como a confusão entre diferentes expressões, sugerem certa carência no que diz respeito à avaliação quantitativa do envolvimento parental (Gomes et al., 2014). Outro estudo de natureza semelhante desenvolvido por Carvalho e Barham (2016) apresentou dados parecidos em relação à coparentalidade. Os pesquisadores identificaram oito instrumentos internacionais que avaliam o construto, porém somente três apresentaram evidências satisfatórias de validade e precisão.

Em relação às amostras, evidencia-se a ampla variedade na faixa etária das crianças, sendo que as investigações envolveram pais e mães com filhos desde a idade pré-natal até a adolescência. Essa mesma constatação foi observada anteriormente, em uma revisão que analisou estudos brasileiros sobre o papel paterno no desenvolvimento infantil (Bueno \& Vieira, 2014) e pode retratar o interesse da produção científica em abarcar fases variadas do desenvolvimento infantil (Gomes et al., 2014). Todavia, questiona-se a respeito da generalização dos resultados a partir de faixas etárias tão amplas, uma vez que as peculiaridades do desenvolvimento psicológico infantil em cada fase podem ocasionar diferentes respostas ao comportamento dos pais divorciados. Mosmann et al. (2017), por exemplo, avaliaram associações entre conjugalidade, parentalidade e coparentalidade com problemas comportamentais dos filhos, e identificaram que as crianças com até sete anos e o grupo de adolescentes entre 11 e 15 anos foram os que mais apresentaram problemas de comportamento de externalização.

Em concordância com pesquisas anteriores (Grzybowski \& Wagner, 2010; Macarini et al., 2010), houve predomínio de mães como participantes nas amostras. Nesse sentido, mesmo que o pai esteja assumindo, gradativamente, maior representatividade nas pesquisas científicas ao longo da história da psicologia, a ênfase na interação entre mãe e criança foi prevalecente, bem como a maior facilidade de acesso às mães por parte dos pesquisadores (Gomes et al., 2014; Macarini et al., 2010; Grzybowski \& Wagner, 2010). Condizente com esses dados, Grzybowski e Wagner (2010) afirmam que as mães se envolvem mais com a criança após a dissolução conjugal. Dados do Instituto Brasileiro de Geografia e Estatística (IBGE) corroboram, dado que 74.4\% das mães ficam responsáveis pela guarda em casos de divórcios judiciais. Atenta-se, ainda, para o fato de que algumas investigações utilizaram como única base o relato das mães. Isso pode ocorrer devido à 
dificuldade de acesso ao pai (Bueno \& Vieira, 2014), porém tende a ser um dado parcial, especialmente nos casos em que há algum tipo de conflito coparental (McGene \& King, 2012; Viri, 2014; Goldberg, 2015).

Os progenitores do sexo masculino, que fazem parte importante do principal microssistema da criança, deveriam atuar como provedores de mecanismos de proteção, fornecendo carinho, cuidados, estabilidade e satisfação das necessidades dos filhos, aspectos que compõe uma parentalidade positiva (Pereira et al., 2015). Embora a literatura científica ainda constate que esse papel é realizado preponderantemente pelas mulheres, em alguns estudos sobre envolvimento parental, observou-se a influência paterna positiva para o desenvolvimento dos filhos, em termos cognitivos e comportamentais (Bueno \& Vieira, 2014; Stallman \& Ohan, 2016; Tanskanen \& Erola, 2017). Mais especificamente, cita-se a pesquisa com pais não residentes de Tanskanen e Erola (2017), que identificou associação positiva entre envolvimento paterno e realizações cognitivas e educacionais dos filhos.

Destaca-se que em revisão de literatura mais recente, Oliveira e Crepaldi (2018) sistematizaram estudos que mostraram associações positivas entre envolvimento paterno, desenvolvimento saudável e aumento da autoestima e do bem-estar da criança, e associações negativas com problemas de comportamento internalizantes e externalizantes na infância. Dessa forma, mesmo que a importância da figura do pai na literatura científica seja uma dedução recente, o envolvimento paterno tende a relacionar-se positivamente a diversos elementos de saúde psicológica dos filhos (Bueno \& Vieira, 2014).

Ao alinhar os fenômenos abordados por este estudo a partir das investigações compiladas, observa-se associação tanto entre envolvimento parental e aspectos da coparentalidade (Finzi-Dottan \& Cohen, 2016; Stallman \& Ohan, 2016) quanto desses fenômenos com algumas variáveis exploradas nas investigações sistematizadas pela revisão. Alguns achados sugerem que a proximidade física do pai com a criança é um fator relevante para a qualidade do envolvimento parental. Pais separados que em algum momento tiveram proximidade tanto com a ex-parceira quanto com o filho, bem como aqueles que detinham a custódia do filho, apresentavam escores mais elevados de envolvimento parental (Finzi-Dottan \& Cohen, 2016; Waller \& Emory, 2014). O mesmo parece ocorrer com a coparentalidade, sendo que nos casos em que o pai se encontra mais distante fisicamente da criança, há tendência de prejuízo à coparentalidade (McGene \& King 2012; Viry, 2014).

Alguns estudos exploraram os impactos das mudanças de configuração familiar dos excônjuges na relação coparental e no envolvimento dos pais divorciados com a criança. De acordo com McNamme (2014), o recasamento da mãe parece estimular o maior envolvimento do pai divorciado com a criança. Meggiolaro e Ongaro (2015) e Madhavan et al. (2016) chegaram à conclusão inversa. Outra investigação anterior (Kalmijn, 2015) revelou que o recasamento da mãe não afeta a qualidade do vínculo do pai com a criança. Observa-se, ainda, que no caso do envolvimento parental das mães, contrariamente, uma nova união conjugal do pai relacionou-se com o aumento do contato materno com a criança (Meggiolaro \& Ongaro, 2015).

Já no que concerne à coparentalidade, as mudanças no arranjo familiar pós divórcio do pai influenciaram mais negativamente a coparentalidade do que as mudanças na estrutura familiar da mãe e, em ambos os casos, os níveis de coparentalidade cooperativa diminuíram com o passar do tempo (Madhavan et al., 2016; McGene \& King, 2012). Quando os homens tinham uma criança com outra parceira, havia um impacto negativo 
na coparentalidade, contrariamente ao que ocorreu com as mães (Goldberg \& Carlson, 2015). Dessa forma, é notável que a conexão entre envolvimento parental, coparentalidade e recasamento dos pais ainda carece de constatações científicas mais conclusivas.

Quanto às demais contribuições sobre coparentalidade, esta revisão sistemática indicou associações positivas entre coparentalidade e indicativos de saúde psicológica nas famílias após o divórcio, tanto no que concerne ao ajustamento infantil, quanto dos pais. Resultados referentes aos progenitores indicaram que a coparentalidade cooperativa associou-se positivamente à satisfação com a vida, ao padrão de vinculação seguro e a melhores desfechos de ajustamento psicológico (Lamela et al., 2013; Lamela et al., 2016). A coparentalidade positiva relacionou-se, ainda, a melhores índices de habilidades sociais e ajustamento psicológico nas crianças (Lamela et al., 2016), e negativamente com comportamentos internalizantes (Beckmeyer et al., 2014; Viry, 2014) e externalizantes (Lamela et al., 2016; Viry, 2014). Esses achados, quando reunidos, parecem condizer com o fato de que o funcionamento familiar como um todo é significativamente afetado pela relação coparental, antes e depois do divórcio (Lamela et al., 2016; Stallman \& Ohan, 2016).

Já a coparentalidade conflituosa esteve associada positivamente a desfechos psicológicos menos saudáveis dos pais (Lamela et al., 2013), envolvendo aumento do estresse parental (Petren et al., 2017). Esse dado mostra-se coerente com outros resultados da literatura, pois quando a coparentalidade apresenta-se prejudicada, os níveis de sintomas depressivos e estresse dos pais mostram-se muito elevados (Solmeyer \& Feinberg, 2011). A coparentalidade com altos níveis de conflito também esteve positivamente associada a maior presença de problemas de internalização e de externalização (Beckmeyer et al., 2014; Lamela et al., 2016) e negativamente associada ao comportamento pró-social nas crianças (Beckmeyer et al., 2014; Viry, 2014).

Esses achados se mantêm coerentes com os resultados dos primeiros estudos sobre coparentalidade com famílias divorciadas da década de 1980, de acordo com Feinberg (2003). O autor ressalta que tais estudos mostravam, já naquela época, que não era o divórcio, por si só, nem sequer particulares acordos de custódia, que afetavam negativamente a adaptação da criança, mas sim um conjunto de fatores pós-divórcio, sendo o mais importante o conflito interparental. Além disso, a relação conjugal anterior à criança também tem se mostrado como um fator importante para a coparentalidade antes e depois do divórcio (Goldberg e Carlson, 2015). Visto que a literatura tem mostrado que esse prejuízo no ajustamento das crianças pode se dar por diversas variáveis não exploradas envolvidas no processo de separação conjugal, para além do próprio divórcio em si, faz-se ainda mais relevante que novas pesquisas explorem de maneira detalhada o papel da coparentalidade nesse interjogo.

Os estudos sobre coparentalidade também apontam a relação entre coparentalidade e percepção das mães sobre a parentalidade dos ex-parceiros (Petren et al., 2017; Russell et al., 2016). As crenças, percepções e atitudes das mães diante da função do pai podem promover ou impedir maiores níveis de participação do pai no cuidado direto com os filhos. O endossamento da parentalidade do pai por parte da mãe da criança tende a promover um senso se competência paterna elevado (Belsy et al., 1995) e aumentar a probabilidade do pai de adotar práticas paternas positivas e estimular o suporte coparental com a ex-parceira (Böing \& Crepaldi, 2016). Há dados retratando, inclusive, que a percepção materna da coparentalidade e o envolvimento da mãe funcionam como preditores do envolvimento do pai (Hui-Hua, 2013). 
Amato (2001) apontou que os estudos da década de 1990 relatam maior efeito do divórcio e piores pontuações de ajustamento infantil do que aqueles publicados na década de 80. Mesmo na década seguinte, as pesquisas publicadas entre 2000 e 2010 seguiram mostrando esses mesmos achados (Amato, 2010). Em ambas as revisões, os piores níveis de ajustamento infantil são discutidos tanto pelo possível aumento de conflito interparental quanto por dificuldades financeiras. Por fim, as pesquisas analisadas pelo presente estudo parecem corroborar esses achados, sendo que tanto a coparentalidade quanto o envolvimento parental influenciam no desenvolvimento das crianças, enquanto promovem a parentalidade positiva de ambos os progenitores mesmo após o divórcio, atuando como um mecanismo de proteção ao desenvolvimento infantil, independentemente da configuração familiar.

As investigações sobre coparentalidade e sobre envolvimento parental exploraram, na sua grande maioria, elementos distintos. Porém, como produto da presente revisão, destacam-se dois elementos comuns principais: o impacto negativo do conflito coparental em ambos os construtos e a associação tanto da coparentalidade quanto do envolvimento parental com ajustamento infantil. A relação entre recasamento dos progenitores e exercício da parentalidade também foi comum entre as pesquisas, porém sem consenso nos achados sobre envolvimento parental.

É importante pontuar que os dados encontrados por este estudo apresentam limitações. Devido ao caráter intrínseco à proposta desta revisão sistemática, estudos teóricos não foram incluídos. Dessa forma, sugere-se explorar ensaios teóricos ou outras modalidades de revisão de literatura (integrativa ou bibliométrica) que gerem resultados complementares aos que já foram encontrados ou mesmo, novas descobertas que venham a questioná-los. Sugerese, ainda, que futuras pesquisas sobre as temáticas investigadas adotem faixas etárias com delimitações mais estreitas, para que os resultados possam ser interpretados a partir do conhecimento científico sobre as características das fases do desenvolvimento típico infantil.

Destaca-se, ainda, a necessidade de investigações quantitativas em âmbito nacional para mapear a qualidade e a relação entre coparentalidade, envolvimento parental e práticas parentais das famílias binucleares brasileiras. Estudos comparativos entre diferentes culturas também poderiam ser interessantes para delimitar com mais clareza o significado desses fenômenos no cotidiano de diferentes famílias. Além disso, pesquisas com foco na figura do pai ainda são mais escassas e trariam elementos complementares aos resultados atuais. Outro campo de exploração diz respeito à avaliação de fatores contextuais (por exemplo, questões socioeconômicas, rede de apoio e/ou histórico familiar) que poderiam impactar positiva ou negativamente nas variáveis abordadas por este estudo no contexto de separação conjugal.

A família não deixa de existir após a dissolução do casamento, mas é obrigada a se reconfigurar. Quando o casal tem filhos, os desafios ligados às práticas parentais positivas, à coparentilidade e ao envolvimento dos pais com a criança parecem ser ampliados. Nesse sentido, espera-se que os resultados deste estudo colaborem para que outros pesquisadores amplifiquem o entendimento sistêmico dos fenômenos aqui explorados, especialmente na busca de outras alternativas metodológicas para explorar as práticas parentais e o envolvimento paterno na dinâmica de famílias que passem pelo processo de divórcio. Essa revisão sistemática pode servir como base, ainda, para a elaboração de novas pesquisas empíricas que venham a fornecer dados para fins de diagnóstico e intervenção de psicólogos e outros profissionais que atuam com famílias binucleares, seja em contexto familiar ou em grupos de intervenção. 


\section{Referências}

Abidin, R., \& Konold, T. (1999). Parenting Alliance Measure - Professional manual. Psychological Assessment Resources.

Ahrons, C. R. (1981). The continuing coparental relationship between divorced spouses. American Journal of Orthopsychiatry, 5, 415-428. doi: 10.1111/j.19390025.1981.tb01390.x

Ahrons, C. (1994). O bom divórcio. Como manter a família unida quando o casamento acaba. Objetiva.

Ahrons, C. R., \& Miller, R. B. (1993). The effect of the postdivorce relationship on paternal involvement: A longitudinal analysis. American Journal of Orthopsychiatry, 63(3), 441-450. https://doi.org/10.1037/h0079446

Amato, P. R. (2001). Children of divorce in the 1990s: An update of the Amato and Keith (1991). Journal of Family Psychology, 15(3), 355-370. http://dx.doi.org/10.1037/08933200.15.3.355

Amato, P. R. (2010). Research on Divorce: continuing trends and new developments. Journal of Marriage and Family, 72(3), 650-666. https://doi.org/10.1111/j.17413737.2010.00723.x

Arnold, D.S., O'Leary, S.G., Wolff, L.S., \& Acker, M.M. (1993). The Parenting Scale: a measure of dysfunctional parenting in discipline situations. Psychological Assessment, 5(2),137-144. http://dx.doi.org/10.1037/1040-3590.5.2.137

Belsky, J., Crnic, K., \& Gable, S. (1995). The determinants of coparenting: Spousal differences and daily hassles. Child Development, 66(3), 629-642. https://doi. org/10.2307/1131939

Beckmeyer, J.J., Coleman, M., \& Ganong, L. H. (2014). Postdivorce coparenting typologies e children's adjustment. Family Relationships, 63(4), 526-537. https://doi. org/10.1111/fare.12086

Böing, E., \& Crepaldi, M. (2016). Relação pais e filhos: compreendendo o interjogo das relações parentais e coparentais. Educar em Revista, 59, 17-33. http://dx.doi. org/10.1590/0104-4060.44615

Buehler, C., \& Trotter, B. B. (1990). Nonresidential and residential parents' perceptions of the former spouse relationship and children's social competence following marital separation: Theory and programmed intervention. Family Relations, 39, 395-404. doi:10.2307/585219

Bueno, R. K., \& Vieira, M. L. (2014). Análise de estudos brasileiros sobre o pai e o desenvolvimento infantil. Psicologia Argumento, 32(76), 151-159. http://dx.doi. org/10.7213/psicol.argum.32.076.AO10

Brito, L. M. T., Cardoso, A. R., \& Oliveira, J. D. G. (2010). Debates entre pais e mães divorciados: um trabalho com grupos. Psicologia: Ciência e Profissão, 30(4), 810823. https://doi.org/10.1590/S1414-98932010000400011

Carvalho, T. R., \& Barham, E. J. (2016). Instrumentos para avaliar a coparentalidade: uma comparação de suas propriedades psicométricas. Avaliação Psicológica, 15(2), 207-215. https://doi.org/10.15689/ap.2016.1502.09 
Choe, D. E., Olson, S. L., \& Sameroff, A. J. (2013). The interplay of externalizing problems and physical and inductive discipline during childhood. Developmental psychology, 49(11), 2029-2039. https://doi.org/10.1037/a0032054

Costa, C. B., Machado, M. R., Schmeider, M. C., \& Mosmann, C. P. (2017). Subsistema coparental: revisão sistemática de estudos empíricos. PSICO, 48(4), 339-351. https://doi.org/10.15448/1980-8623.2017.4.25386

Feinberg, M. E. (2003). The Internal Structure and Ecological Context of Coparenting: a Framework for Research and Intervention. Parenting: Science and Practice, 3(2), 95-131. https://doi.org/10.1207/S15327922PAR0302_01

Feinberg, M., Brown, L., \& Kan, M. (2012) A multi-domain self-report measure of coparenting. Parenting: Science and Practice, 12(1), 1-21. https://doi.org/10.1080/15295192.2012.638870

Finzi-Dottan, R., \& Cohen, O. (2016). Predictors of involvement and warmth of custodial fathers in Israel: comparison with married and noncustodial divorced fathers. Family Process, 55(1), 171-87. https://onlinelibrary.wiley.com/doi/abs/10.1111/famp.12124

Flouri, E., Midouhas, E., Narayanan, M.K. (2016). The relationship between father involvement and child problem behaviour in intact families: A 7-year cross-lagged study. Journal of Abnormal Child Psychology, 44(5), 1011-1021. Doi: 10.1007/s10802-015-0077-9

Gershoff, E. T., Grogan-Kaylor, A., Lansford, J. E., Chang, L., Zelli, A., Deater-Deckard, K., \& Dodge, K. A. (2010). Parent discipline practices in an international sample: Associations with child behaviors and moderation by perceived normativeness. Child Development, 87(2), 487-502. https://srcd.onlinelibrary.wiley.com/ doi/10.1111/j.1467-8624.2009.01409.x

Goldberg, J. (2015). Coparenting and nonresident fathers' monetary contributions to their children. Journal of Marriage and the Family, 77, 612-627. https://doi.org/10.1111/ jomf.12191

Goldberg, J. S., \& Carlson, M. J. (2015). Patterns and predictors of coparenting after unmarried parents part. Journal of Family Psychology, 29(3), 416-426. https://doi. org/10.1037/fam0000078

Goldsmith, J. (1980). Relationship between former spouses: Descriptive findings. Journal of Divorce, 4, 1-19. https://doi.org/10.1300/J279v04n02_01

Gomes, L. B., Bossardi, C. N., Cruz, R. M., Crepaldi, M. A., \& Vieira, M. L. (2014). Propriedades psicométricas de instrumentos de avaliação do envolvimento paterno: revisão de literatura. Avaliação Psicológica, 13(1), 19-27.

Grzybowski, L. S., \& Wagner, A. (2010). O envolvimento parental após a separação/ divórcio. Psicologia: Reflexão e Crítica, 23(2), 289-298. http://dx.doi.org/10.1590/ S0102-79722010000200011

Gulliford, H., Deans, J., Frydenberg,E., \& Liang, R. (2015). Teaching coping skills in the context of positive parenting within a preschool setting. Australian Psychologist, 50(3), 219-231. http://dx.doi.org/10.1111/ap.12121

Guttman, M., Mowder, B. A., \& Yasik, A. E. (2006). The ACT Against Violence Training Program: a preliminary investigation of knowledge gained by early childhood professionals. Professional Psychology: Research and Practice, 37(6), 717-723. http://dx.doi.org/10.1037/0735-7028.37.6.717 
Hawkins, A. J., Bradford, K. P., Palkovitz, R., Christiansen, S. L., Day, R. D., \& Call, V. R. (2002). The inventory of father involvement: a pilot study of a new measure of father involvement. Journal of Men's Studies, 2, 183-194. https://doi.org/10.3149/jms.1002.183

Hui-Hua, C. (2013). Couple relationship quality, coparenting, and fathering in Taiwan. Early Child Development and Care, 183(6), 827-842. https://doi.org/10.1080/03 004430.2012 .723443

Instituto Brasileiro de Geografia e Estatística. (2016). Registro Civil - Informativo 2016. www.ibge.gov.br

Johnston, C., \& Mash, E. J. (1989). A measure of parenting satisfaction and efficacy. Journal of Clinical Child Psychology, 18, 167-175.

Kalmijn, M. (2015). Father-child relations after divorce in four european countries: patterns and determinants. Comparative Population Studies, 40(3), 251-276. http://dx.doi. org/10.12765/CPoS-2015-10en

Kobarg, A. P. R., Vieira, V., \& Vieira, M. L. (2010). Validação da Escala de Lembranças sobre Práticas Parentais (Embu). Avaliação Psicológica, 9(1), 77-85.

Lamb, M. E., Pleck, J. H., Charnov, E. L., \& Levine, J. A. (1985). Paternal behavior in humans. American Zoologist, 25(3), 883-894. http://dx.doi.org/10.1093/icb/25.3.883

Lamela, D., Castro, M., \& Figueiredo, B. (2010). Pais por inteiro: avaliação preliminar da eficácia de uma intervenção em grupo para pais divorciados. Psicologia: Reflexão e Crítica, 23(2), 334-344. http://dx.doi.org/10.1590/S0102-79722010000200016

Lamela, D., Figueiredo, B., \& Bastos, A. (2010). Adaptação ao divórcio e relações coparentais: contributos da teoria da vinculação. Psicologia: Reflexão e Crítica, 23(3), 562-574. http://dx.doi.org/10.1590/S0102-79722010000300017

Lamela, D., Figueiredo, B., \& Bastos, A. (2013). Perfis de vinculação, coparentalidade e ajustamento familiar em pais recém-divorciados: diferenças no ajustamento psicológico. Psicologia: Reflexão e Crítica, 26(1), 19-28. http://dx.doi.org/10.1590/ S0102-79722013000100003

Lamela, D., Figueiredo, B., Bastos, A., \& Feinberg, M. E. (2016). Typologies of postdivorce coparenting and parental well-being, parenting quality and children's psychological adjustment. Child Psychiatry and Human Development, 47(5), 716728. http://dx.doi.org/10.1007/s10578-015-0604-5

Macarini, S. M., Martins, G. D. F., Minetto, M. J., \& Vieira, M. L. (2010). Práticas parentais: uma revisão da literatura brasileira. Arquivos Brasileiros de Psicologia, 62(1), 119-134.

Machado, M. R., \& Mosmann, C. P. (2019). Dimensões negativas da coparentalidade e sintomas internalizantes: a regulação emocional como mediadora. Psicologia: Teoria e Pesquisa, 35. https://dx.doi.org/10.1590/0102.3772e35nspe12

Madhavan, S., Richter, L., \& Norris, S. (2016). Father contact following union dissolution for low-income children in urban South Africa. Journal of Family Issues, 37(5), 622644. https://doi.org/10.1177/0192513X14532255

Margolin, G., Gordis, E. B., \& John, R. S. (2001). Coparenting: A link between marital conflict and parenting in two-parenting families. Journal of Family Psychology, 15, 3-21. https://doi.org/10.1037/0893-3200.15.1.3 
McGene, J., \& King, V. (2012). Implications of New Marriages and Children for Coparenting in Nonresident Father Families. Journal of Family Issues, 33(12), 1619-1641. https:// doi.org/10.1177/0192513X12437150

McNamee, C. B., Amato, P., \& King, V. (2014). Nonresident father involvement with children and divorced women's likelihood of remarriage. Journal of Marriage and Family, 76(4), 862-874. https://onlinelibrary.wiley.com/doi/abs/10.1111/jomf.12118

Meggiolaro, S., \& Ongaro, F. (2015). Non-resident parent-child contact after marital dissolution and parental repartnering: evidence from Italy. Demographic Research, 33(40), 1137-1151. https://doi.org/10.4054/DemRes.2015.33.40

Moher D., \& Tsertsvadze, A. (2006). Systematic reviews: when is an update an update? The Lancet, 367(9514), 881-883. https://doi.org/10.1016/S0140-6736(06)68358-X

Mosmann, C. P., Costa, C. B., Einsfeld, P., Silva, A. G. M., \& Koch, C. (2017). Conjugalidade, parentalidade e coparentalidade: associações com sintomas externalizantes e internalizantes em crianças e adolescentes. Estudos de Psicologia - Campinas, 34(4), 487-498. https://doi.org/10.1590/1982-02752017000400005

Oliveira, J. L. A. P., \& Crepaldi, M. A. (2018). Relação entre o pai e os filhos após o divórcio: revisão integrativa da literatura. Actualidades en Psicología, 32(124), 91-109. https://doi.org/10.15517/ap.v32i124.29021

Pereira, A. I., Goes, A. R., \& Barros, L. (2015). Promoção da parentalidade positiva: intervenções psicológicas com pais de Crianças e adolescentes. Lisboa: Coisas de Ler

Petren, R. E., Ferraro, A. J., Davis, T. R., \& Pasley, K. (2017). Factors Linked with coparenting support and conflict after divorce. Journal of Divorce \& Remarriage, 58(3), 145160. https://doi.org/10.1080/10502556.2017.1300013

Rohner, R. P., Khaleque, A., \& Cournoyer, D. E. (2005). Parental acceptance-rejection theory, methods, evidence, and implications. In R. P. Rohner \& A. Khaleque (Eds.), Handbook for the study of parental acceptance-rejection (4th ed., pp. 1-35). Storrs, CT: Rohner Research Publications.

Russell, L. T., Beckmeyer, J. J., Coleman, M., \& Ganong, L. (2016). Perceived barriers to post-divorce coparenting: differences between men and women and associations with coparenting behaviors. Family Relations, 65, 450-461. https:// doi.org/10.1111/fare.12198

Shaw, D.S., \& Emery, R.E. (1987). Parental conflict and other correlates of the adjustment of school aged children whose parents have separated. Journal of Abnormal Child Psychology, 15(2), 269-281. https://10.1007/BF00916354

Shonkoff, J. P., Richter, L., van der Gaag, J., \& Bhutta, Z. A. (2012). An integrated scientific framework for child survival and early childhood development. Pediatrics, 129(2), 460-472. https://doi.org/10.1542/peds.2011-0366

Stallman, H. M., \& Ohan, J. L. (2016). Parenting style, parental adjustment, and co-parental conflict: differential predictors of child psychosocial adjustment following divorce. Behaviour Change, 33(2), 112-126. https://doi.org/10.1017/bec.2016.7

Solmeyer, A. R., \& Feinberg, M. A. (2011). Mother and father adjustment during early parenthood: the roles of infant temperament and coparenting relationship quality. Infant Behavior \& Development, 34, 504-514. https://doi.org/10.1016/j.infbeh.2011.07.006 
Souza, C. D. (2018). Repercussões da coparentalidade e do envolvimento paterno no comportamento da criança pré-escolar em famílias biparentais. Florianópolis, Tese [Doutorado em Psicologia, Universidade Federal de Santa Catarina]. Repositorio Institucional. https://repositorio.ufsc.br/handle/123456789/189948

Tanskanen, A. O., \& Erola, J. (2017). Do nonresident fathers compensate for a lack of household resources? The associations between paternal involvement and children's cognitive and educational assessments in the UK. Research in Social Stratification and Mobility, 48, 32-40. https://doi.org/10.1016/j.rssm.2017.01.002

Viry, G. (2014). Coparenting and children's adjustment to divorce: the role of geographical distance from fathers. Journal of Divorce \& Remarriage, 55(7), 503-526. https:// doi.org/10.1080/10502556.2014.950900

Waller, M. R., \& Emory, A. D. (2014). Parents apart: differences between unmarried and divorcing parents in separated families. Family Court Review, 52(4), 686-703. https://onlinelibrary.wiley.com/doi/abs/10.1111/fcre.12121

Waller, M. R., \& Jones, M. R. (2014). Who is the residential parent? Understanding discrepancies in unmarried parents' reports. Journal of Marriage and Family, 76(1), 73-93. https://doi.org/10.1111/jomf.12087

Zoltowski; A.P., Costa, A. B., Teixeira, M. A. P., Koller, S. H. (2014). Qualidade metodológica das revisões sistemáticas em periódicos de psicologia brasileiros. Psicologia: Teoria e Pesquisa, 30(1), 97-104. http://dx.doi.org/10.1590/S0102-37722014000100012 